\title{
Study on Automatic Arrangement Algorithm for Tower Cranes with Applying Lifting Limit Axis
}

\author{
Kyeong-Tae Jeong and Ji-Yeong Yun and Donghoon Lee* \\ Department of Architectural engineering Hanbat National University Daejeon 34158 Republic of Korea. \\ *Corresponding author. Tel.: +82-010-2663-9331; Email address:donghoon@ hanbat.ac.kr
}

Article History: Received: 10 November 2020; Revised: 12 January 2021; Accepted: 27 January 2021; Published online: 05 April 2021

\begin{abstract}
Recently construction projects are becoming more high-rise, and for this reason, efficient operation of tower crane is very important. Therefore, we conducted a study on the development of automatic arrangement algorithm for the efficient operation of tower crane. In this study, a new concept, the 'lifting limit axis' concept was applied to develop automatic arrangement (optimal arrangement) algorithm of tower crane. Through this process, the 'three-dimensional figure' was created and the research was carried out considering the weight of the material, the working radius of the tower crane, and the lifting capacity. In this study, we carried out the study in three dimensions to apply the concept of 'lifting limit axis', which is different from the existing studies conducted in two dimensions. This is not simply a three-dimensional and twodimensional difference. The reason for this is that the lifting work can be considered by applying the change in the lifting capacity according to the working radius of the tower crane in three dimensions. Therefore, it is a concept that enables highly efficient and stable lifting work. In this study, we developed an algorithm by applying this concept of 'lifting limit axis', which is divided into four steps. The first step is information input, the second step is identifying the intersection area where the tower crane can be arranged, the third step is to arrange the 'three-dimensional figure' and the last step is to select the minimum-cost simulation out of a number of simulation. This algorithm provides the basic guidelines for tower crane arrangement through the above process. In this study, we applied the new concept of 'lifting limit axis'. Therefore, continuous follow-up research is essential, and it is expected that this will lead to an efficient lifting plan of tower crane.

Keywords: Tower crane, Arrangement, Working radius, Lifting limit axis, Three-dimensional figure, Algorithm
\end{abstract}

\section{Introduction}

In recent years, the scale of construction projects has tended to become super-high-rise, large-scale, and complicated[1]. A large amount of material is input in construction work of this scale, and it is very important to transport materials to the right place according to the process plan in construction management[2]. Therefore, in order to improve the efficiency of construction management, it is necessary to efficiently operate the lifting equipment for transporting those materials.

This Among the lifting equipment used in construction projects of the above scale, a tower crane has the largest share[3]. The tower crane is an equipment that can convey materials vertically, and is evaluated to have high work productivity, and has been continuously used in construction projects [4]. In order to operate the tower crane efficiently, a systematic lifting plan must be established, and the plan will have a direct impact on construction period, safety management, process management and construction cost[5]. When establishing a lifting plan for a tower crane, the type and number of equipment, and the arrangement plan must be included. In addition, all matters related to the lifting work must be considered in a complex manner[2]. However, the actual construction site does not establish a lifting plan of the tower crane in a systematic manner, and it is understood that it was established mainly based on the experience and intuition of experts[5].

In this way, there is no standardized regulation regarding the selection and arrangement of the tower crane, which causes problems such as an increase in construction cost and a delay in construction period[6]. In order to solve such problems, researches on selection and arrangement of tower cranes have been actively conducted, and most of the researches are divided into studies using genetic algorithms and studies using mathematical models.

Zhang (1999)[7] developed a mathematical model that can figure out the travel time of the crane hook by assuming the use of multiple tower cranes. Rodrigues (1983)[8] developed a mathematical model for the optimal position selection based on one tower crane. And, Kim (2009)[9] presented a genetic algorithm-based model for material transportation optimization, and Tam (2001)[10] developed a field arrangement gene algorithm model for tower cranes, presented an actual case and proved its potentiality. The above-mentioned studies analyzed the working radius of the tower crane and proceeded with the method of determining the position of the tower crane.

On the other hand, unlike the conventional method, Lim (2012)[11] proposed an innovative idea of arranging the tower crane around the necessary place (IP) where the lifting is required, and based on this, derived an automatic arrangement algorithm of the tower crane. However, the study of Lim (2012)[11] did not consider the lifting capacity of the tower crane, which changes with the distance to the lifting target. This is an important consideration when selecting the specifications of the tower crane, and also important for the safety of the tower crane. For example, when a tower crane with a lifting capacity of 8 tons lifts 8 tons of material at the end of the

*Corresponding author: Donghoon Lee

Department of Architectural engineering Hanbat National University Daejeon 34158 Republic of Korea. Email address:donghoon@hanbat.ac.kr 
working radius, it lifts materials above the rated load. If the overload continues, it causes fatigue fracture and collapse of the tower crane[12].

In this study, the new concept 'lifting limit axis', which has never been seen before, was applied in order to apply the above-mentioned matters related to the arrangement and lifting work of the tower crane to the algorithm more effectively. Also, in order to apply the concept of 'lifting limit axis', unlike the existing research, this study has developed an automatic arrangement algorithm for tower cranes in 3D instead of 2D.

\section{Concept of 'Lifting Limit Axis' and Its Application Method}

\subsection{Concept of 'Lifting Limit Axis'}

This study introduced a new concept called 'lifting limit axis' and developed and researched the automatic arrangement algorithm for tower cranes. Also, in order to apply the 'lifting limit axis', unlike the existing research, this study conducted research in 3D instead of 2D. Figure 1-(1) is a graph of the lifting capacity that a tower crane with a capacity of 8 tons and a Jib length of $40 \mathrm{~m}$ can lift with a working radius. As can be seen in the figure, the lifting capacity is 8 tons within the working radius of 20 to $40 \mathrm{~m}$ in the tower crane, and 4 tons can be lifted within the working radius of 20 to $40 \mathrm{~m}$. Thus, the lifting capacity of the tower crane changes depending on the working radius. possible to where they are mentioned in the text.

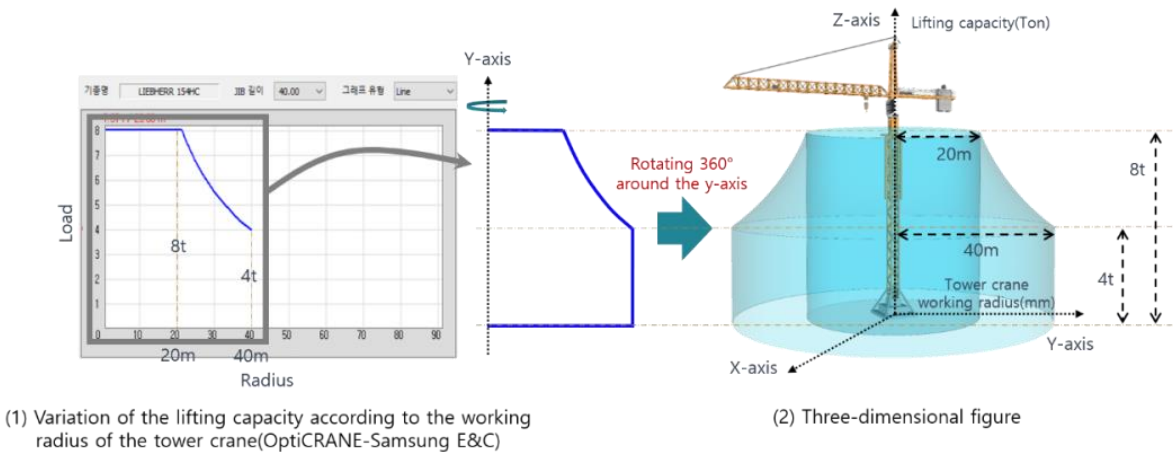

Figure 1 Concept of 'Lifting Limit Axis'

\subsection{Concept of LP (Lifting Point) and expression of working radius (CWR) of TC}

In order to apply the above-mentioned 'three-dimensional figure', it must first find an area where the tower crane can be arranged. In order to find this area, this study expressed the working radius of the tower crane focusing on the LP (Lifting Point) represented in each building as shown in Fig. 3. The 'working radius' expressed is all the same size, and the LP expressed on the building means the point where lifting is required and the point where the material is transported. As shown in fig. 2, an area where three circles drawn centering on each LP(n) intersect can be confirmed. This intersection area is an area where the tower crane can be arranged. When arranging the tower crane in the intersection area, LP(1), LP(2), LP(3) points are included in the working radius of the tower crane. This study applied such a method to arrange the tower crane in the intersection area, and to judge whether the lifting work at the LP(n) point is possible or not. depending on the working radius. possible to where they are mentioned in the text.

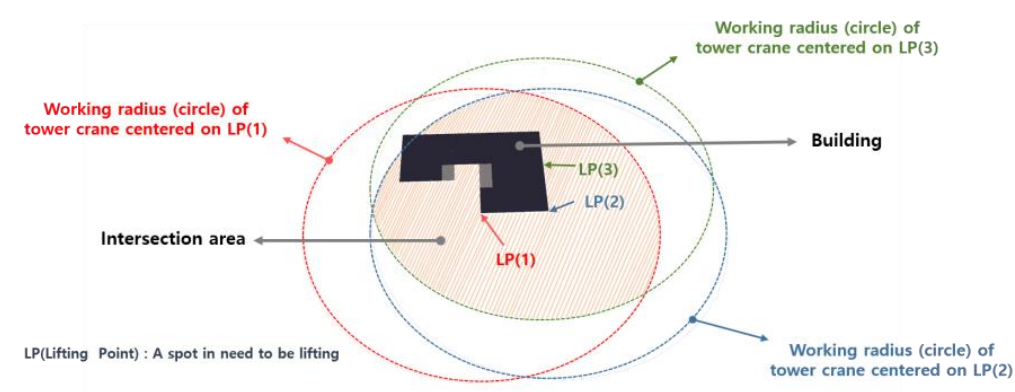

Figure 2 Express the working radius of the tower crane around the LP(n)

\subsection{Expression of maximum weight value of material}


After finding the intersection area where the tower crane can be arranged by the above method, it is necessary to judge whether the lifting work is possible at the LP(n) point by applying the three-dimensional figure. However, the maximum weight value of the material at the LP point expressed on the architectural drawing must be expressed in advance. The method of expressing the maximum weight value of the material at the LP point is as shown in Fig. 3, and the height at this point indicates the maximum weight value. For the maximum weight value of the lifting member, the accurate quantity of members must be calculated from the initial design stage to express the maximum weight value.

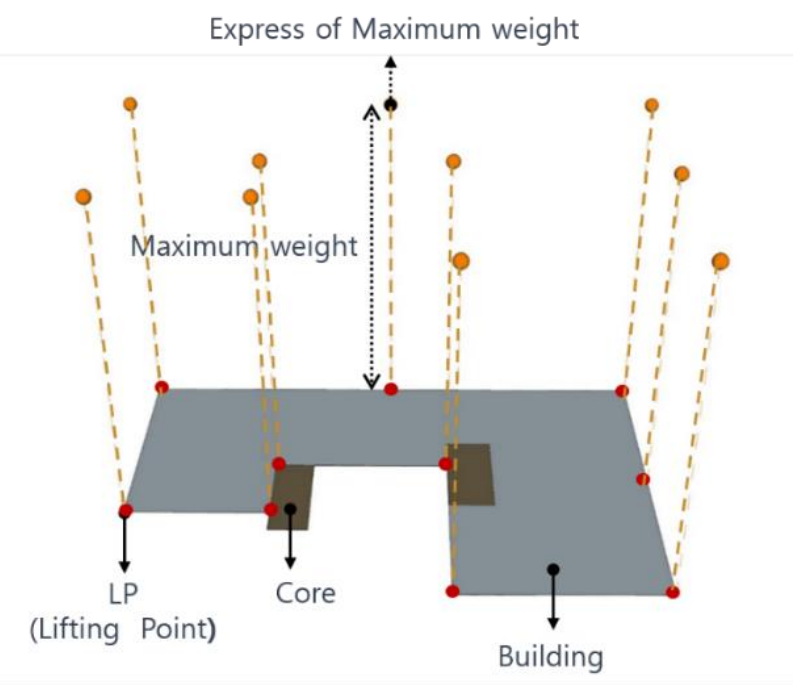

Figure 3 Express of Maximum weight

\subsection{Arrangement of 'Three-dimensional figure'}

If the maximum weight value of the material at the LP(n) point is expressed by the above method, a 'threedimensional figure' is arranged in the intersection area found earlier as shown in Fig. 4. And Fig. 4-(1) shows an arrangement of a 'three-dimensional figure' in the intersection area, and it can be seen that this figure contains the maximum weight values of all LP(n). This means that if the tower crane is arranged in the appropriate position, lifting work can be performed on all LP(n). On the other hand, in Fig. 4-(2), unlike in 4-(1), the 'threedimensional figure' is arranged at different positions in the same intersection area.

Fig. 4-(2) shows that the maximum weight value in LP(1) is not included in the arranged 'three-dimensional figure', which means that when the tower crane is arranged in the corresponding position, the lifting work is possible at all LP(n) points except for LP(1). Through the arrangement method of such figure, this study conducted the basic algorithm development research which searches the appropriate arrangement position of the tower crane.

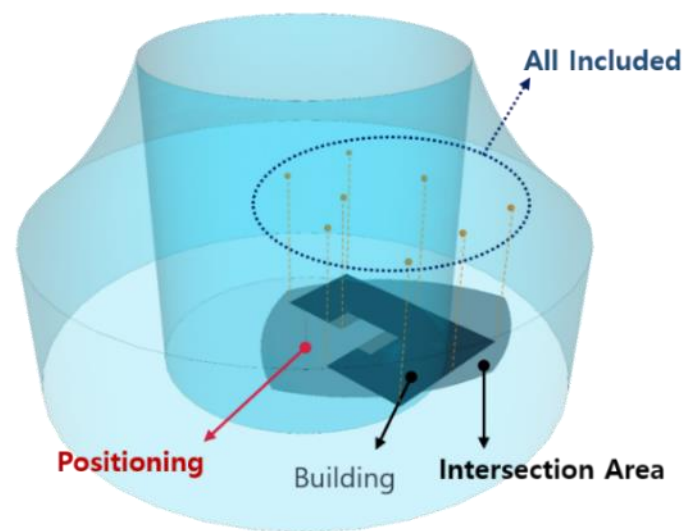

(1)

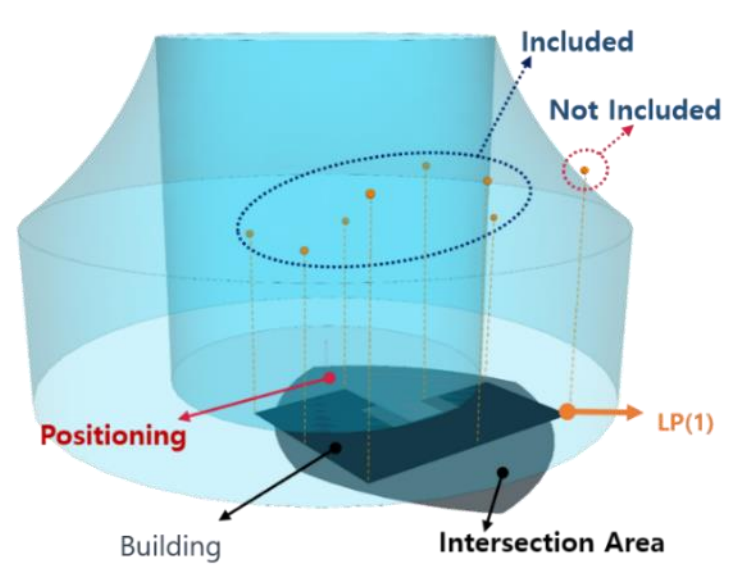

(2)

Figure 4 Arrangement of Three-dimensional figure

\section{Research and Development of TC Automatic Arrangement Algorithm}


This study introduced a new concept called 'lifting limit axis' and developed and researched the automatic arrangement algorithm for tower cranes. Also, in order to apply the 'lifting limit axis', unlike the existing research, this study conducted research

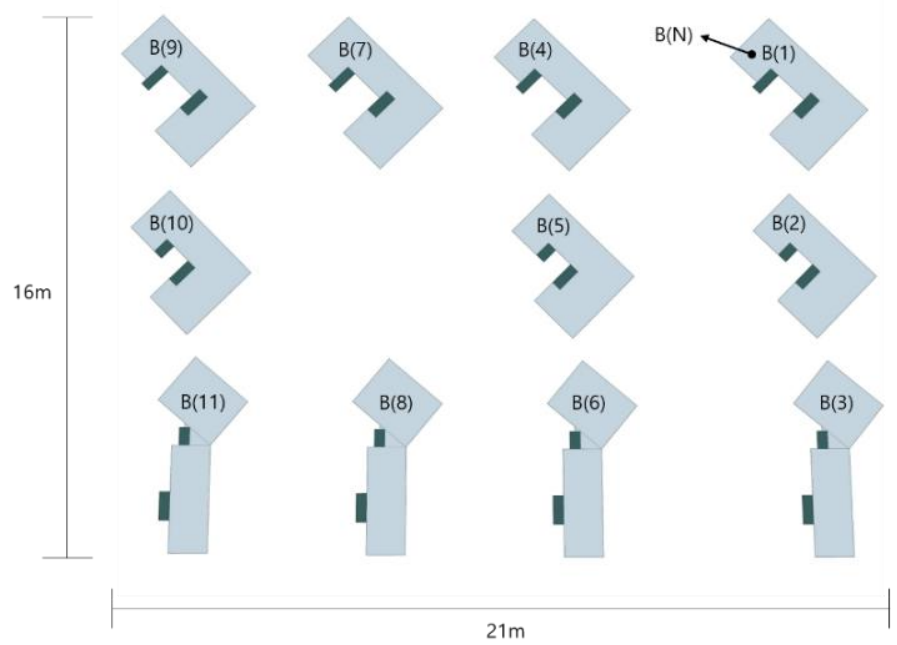

Figure 5 Drawing of High-rise Apartment Construction Site

\subsection{Arrangement of 'Three-dimensional figure'}

The first step of the algorithm is a step in which the user inputs the information of the construction project and the tower crane to be applied. At that time, the construction project information to be input includes construction work drawings, material quantities, and material lifting points, and the tower crane information includes working radius, lifting capacity, and cost (rent, installation, removal). Here, the reason why the cost is included in the tower crane information is that the tower crane is the equipment that is directly reflected in the construction cost[13] and the algorithm selects the arrangement with the lowest cost from the various arrangement simulations that have been derived. In the next place, based on the input information, as shown in Fig. 6, the maximum weight value of the material is expressed on the construction drawing.
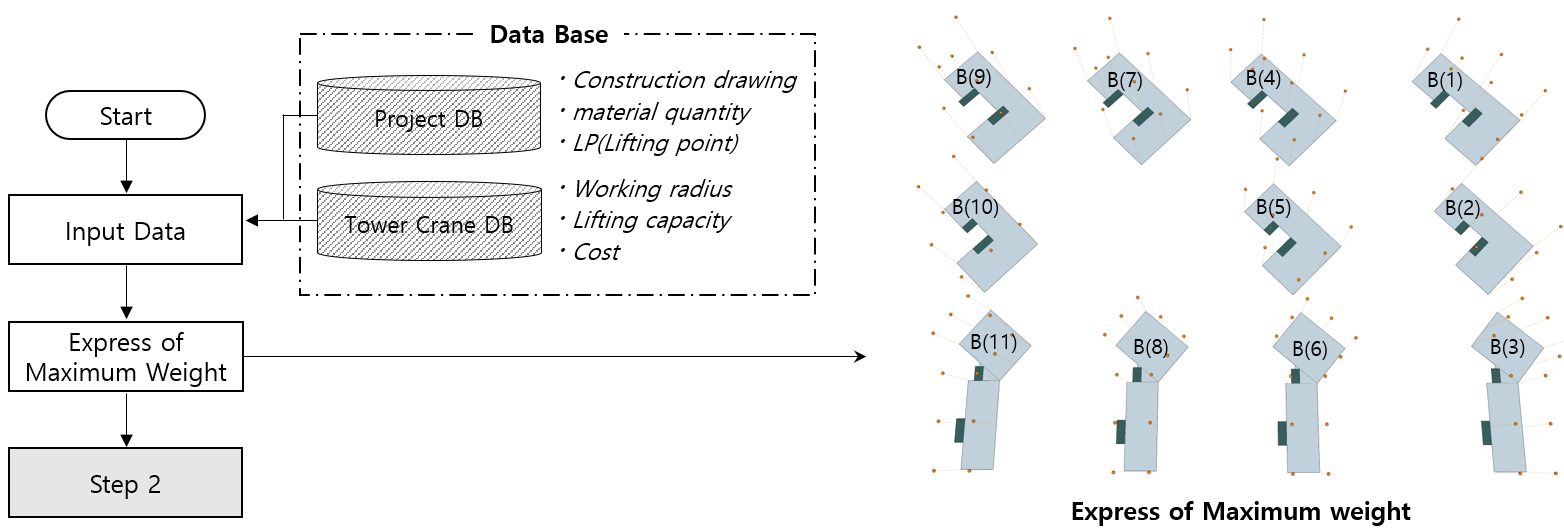

Figure 6 Step 1 Input Project Data \& TC Data

\subsection{Second step of TC's automatic arrangement algorithm}

The second step of the algorithm is the step of finding an area where the 'three-dimensional figure' can be arranged. The start selects the type that the user intends to apply from the types of the tower cranes. At this time, there is no limit to the quantity of tower cranes that can be selected, and the user can select the desired type of tower crane. The first step of the algorithm is a step in which the user inputs the information of the construction project and the tower crane to be applied. In the next place, the working radius of all tower cranes used are expressed centering on each $\mathrm{B}(\mathrm{N})-\mathrm{LP}(\mathrm{n})$, and based on this, the intersection areas ' $\mathrm{A}$ ' and ' $\mathrm{B}$ ' as shown in Fig. 8 are checked and saved. The area 'A' is the intersection area of the working radius drawn around all the LP(n) of the relevant unit, and when arranging the tower crane in this area, the working radius includes all of the LP(n). 
Therefore, in the intersection area 'A', it is possible to know the arrangement position of the tower crane that can perform the lifting work for all of $\mathrm{LP}(\mathrm{n})$. In this study, the notation of the area ' $\mathrm{A}$ ' is $\mathrm{AT}-\mathrm{B}(\mathrm{N})$, and ' $\mathrm{T}$ ' is a type of tower crane. An example of the notation can be seen through Fig. 8(1).

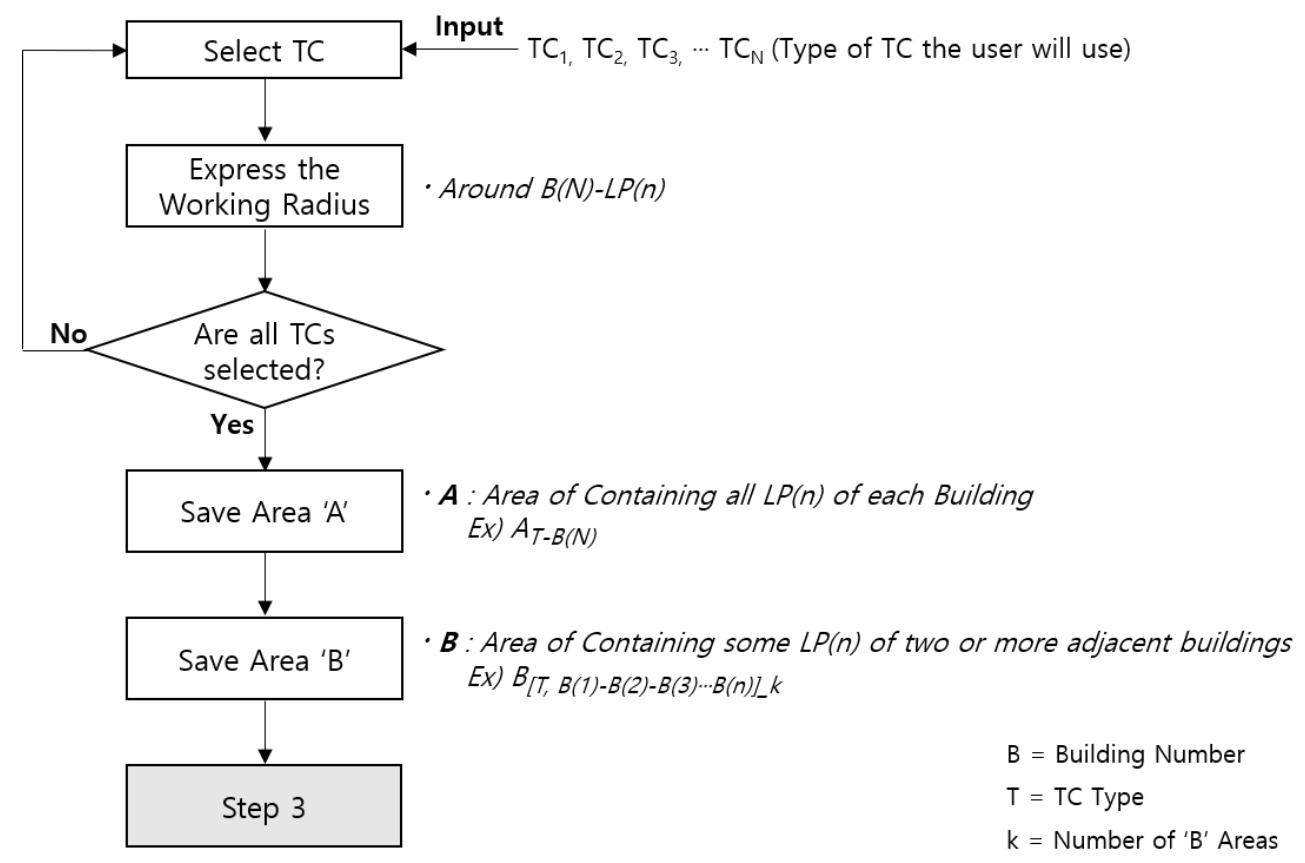

Figure 7 Step 2 Identify Areas where 'Three-dimensional figure' can be Placed

The area 'B' is the intersection area of the tower crane's working radius made around the LP(n) of the adjacent building. When arranging the tower crane in this area, part of the adjacent building LP(n) and other part of the adjacent building LP(n) is included in the working radius. Therefore, in the intersection area 'B', the arrangement position of the tower crane capable of the lifting work can be confirmed with respect to a partial LP(n) of each building. Unlike the area 'A', the area ' $B$ ' is an area created through LP(n) of different buildings, and there exist innumerable areas. Therefore, in Fig. 8 (2), an example of typical area ' $\mathrm{B}$ ' is illustrated. In this study, the notation of the area ' $\mathrm{B}$ ' is $\mathrm{B}[\mathrm{T}, \mathrm{B}(\mathrm{N})-\mathrm{B}(\mathrm{N})-\mathrm{B}(\mathrm{N}) \cdots \mathrm{B}(\mathrm{N})]_{-} \mathrm{k}$, where ' $\mathrm{T}$ ' is the type of tower crane and $\mathrm{k}$ is an innumerable number of area ' $\mathrm{B}$ '. An example of the notation is, as shown in Fig. 8 (2). As shown in the figure, the intersection area ' $\mathrm{B}$ ' created between the $\mathrm{B}(1)$ building and the $\mathrm{B}(2)$ building is indicated as $\mathrm{B}[\mathrm{T}$, $\mathrm{B}(1)-\mathrm{B}(2)] \_\mathrm{k}$.

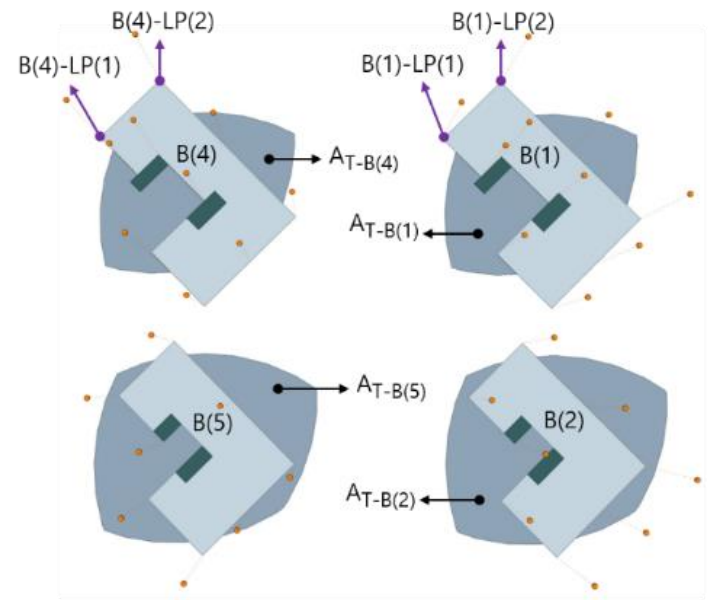

(1) Meaning of 'A' area

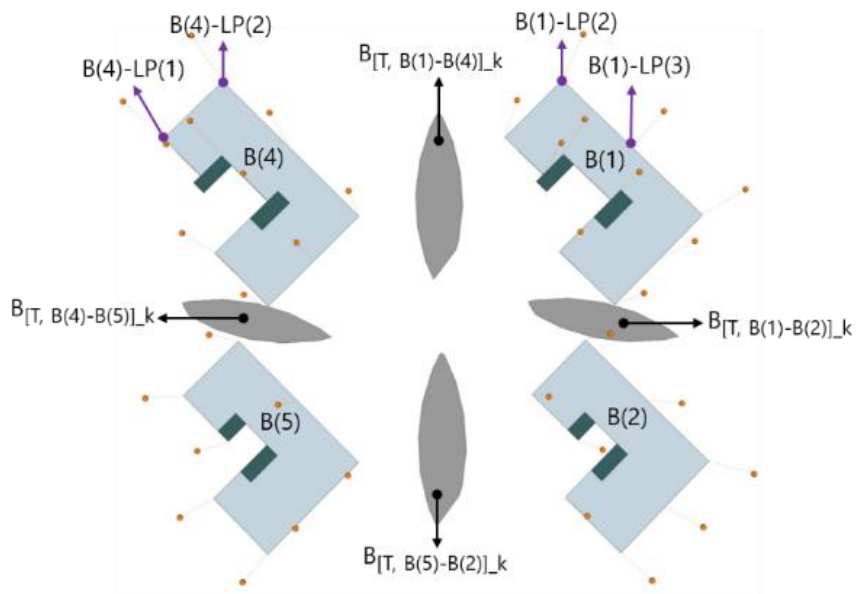

(2) Meaning of 'B' area

Figure 8 Meaning of 'A' and 'B' Areas

\subsection{Third step of TC's automatic arrangement algorithm}

The third step of the algorithm is the step of arranging the 'three-dimensional figure'. The third step begins 
with the selection of $\mathrm{B}(1)$ building. After selecting $\mathrm{B}(1)$, the tower crane is randomly selected to generate a 'three-dimensional figure'. In the next place, as shown in Figure 10, the intersection areas 'A' and 'B' are loaded according to the selected tower crane, followed by random arrangement of the 'three-dimensional figure' to the area ' $A$ ' or ' $B$ '. After randomly arranging the figures, the inclusion of the maximum weight value of each LP(n) is confirmed, and the arrangement is repeated.

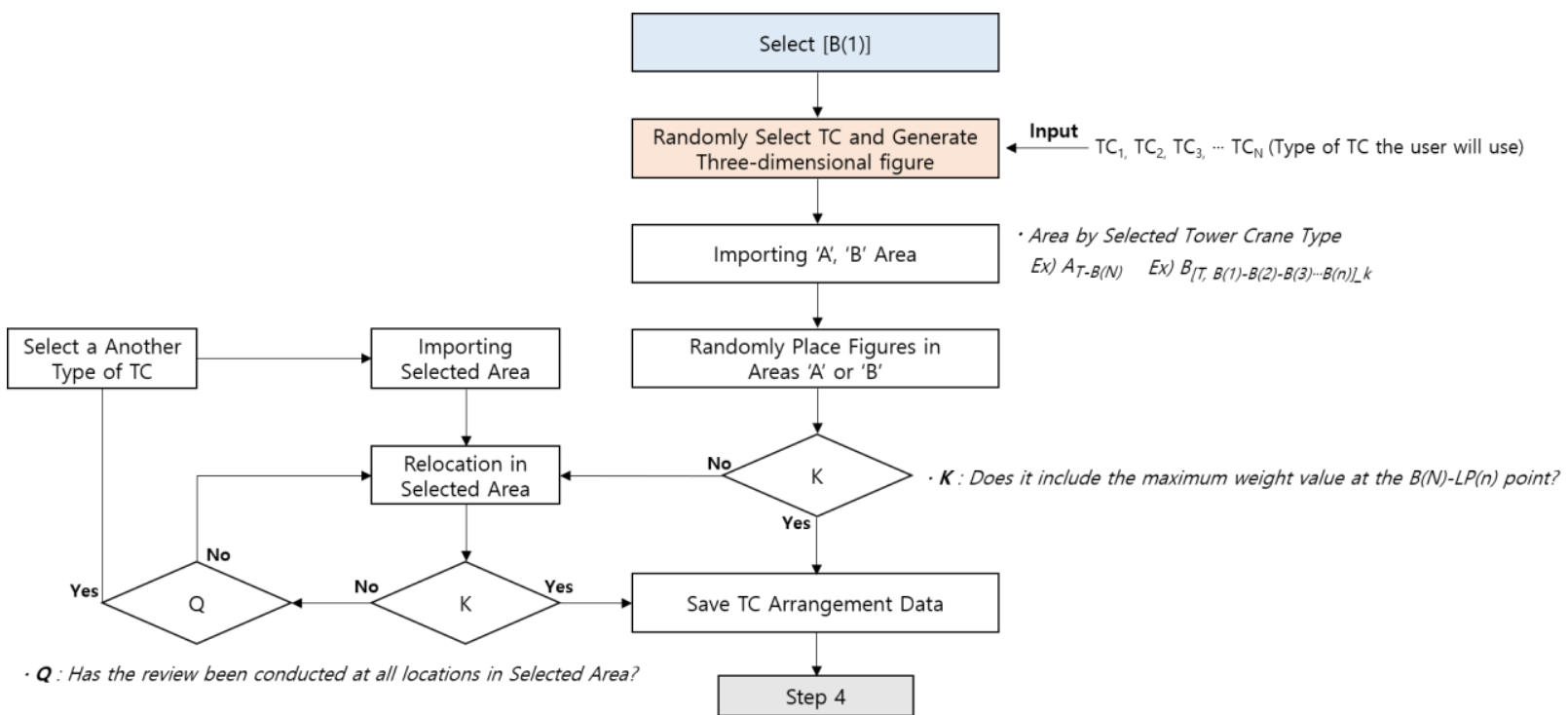

Figure 9 Arrangement of Three-dimensional figure

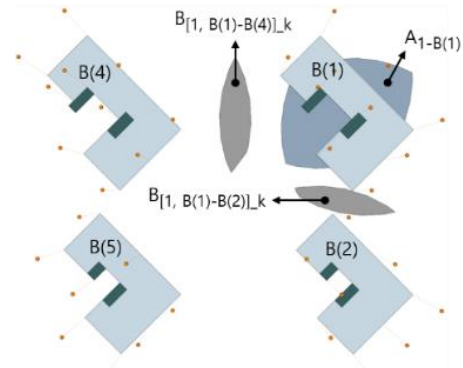

Figure 10 Importing ' $A$ ', 'B'

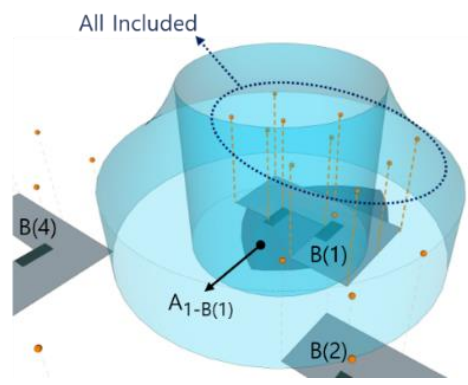

Figure 11 Place 'A' Area

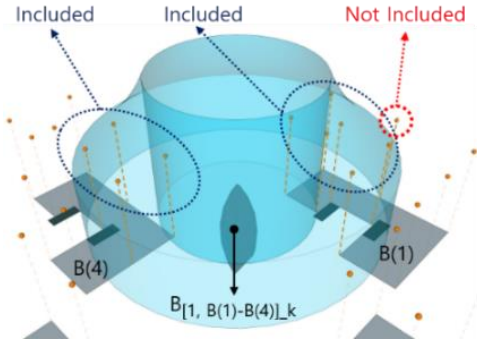

Figure 12 Place 'B' Area

If the 'three-dimensional figure' is arranged in the area ' $A$ ' as shown in Fig. 11, the figure includes the maximum weight values of all LP(n) which is included in the working radius. Thus, it saves arrangement in $\mathrm{B}(1)$ and proceeded to the next step. However, if the 'three-dimensional figure' is arranged in the area 'B' as shown in Fig. 12, the figure does not include the maximum weight value of all LP(n) within the working radius, which requires, the re-arrangement. The rearrangement is proceeded in the intersection area. If all positions have been considered but the maximum weight value is not included, it selects another type of tower crane, loads the intersection area and proceeds with the rearrangement in the same way.

\subsection{Fourth step of TC's automatic arrangement algorithm}

The final stop of the algorithm is to proceed with the 'three-dimensional figure' arrangement and determine the final arrangement of the tower crane through cost analysis. The algorithm at this step is as shown in Fig. 13, and the beginning is as follows. After the arrangement of $\mathrm{B}(1)$ is completed by the algorithm of the third step above, the arrangement is proceeded to $\mathrm{B}(2)$. 


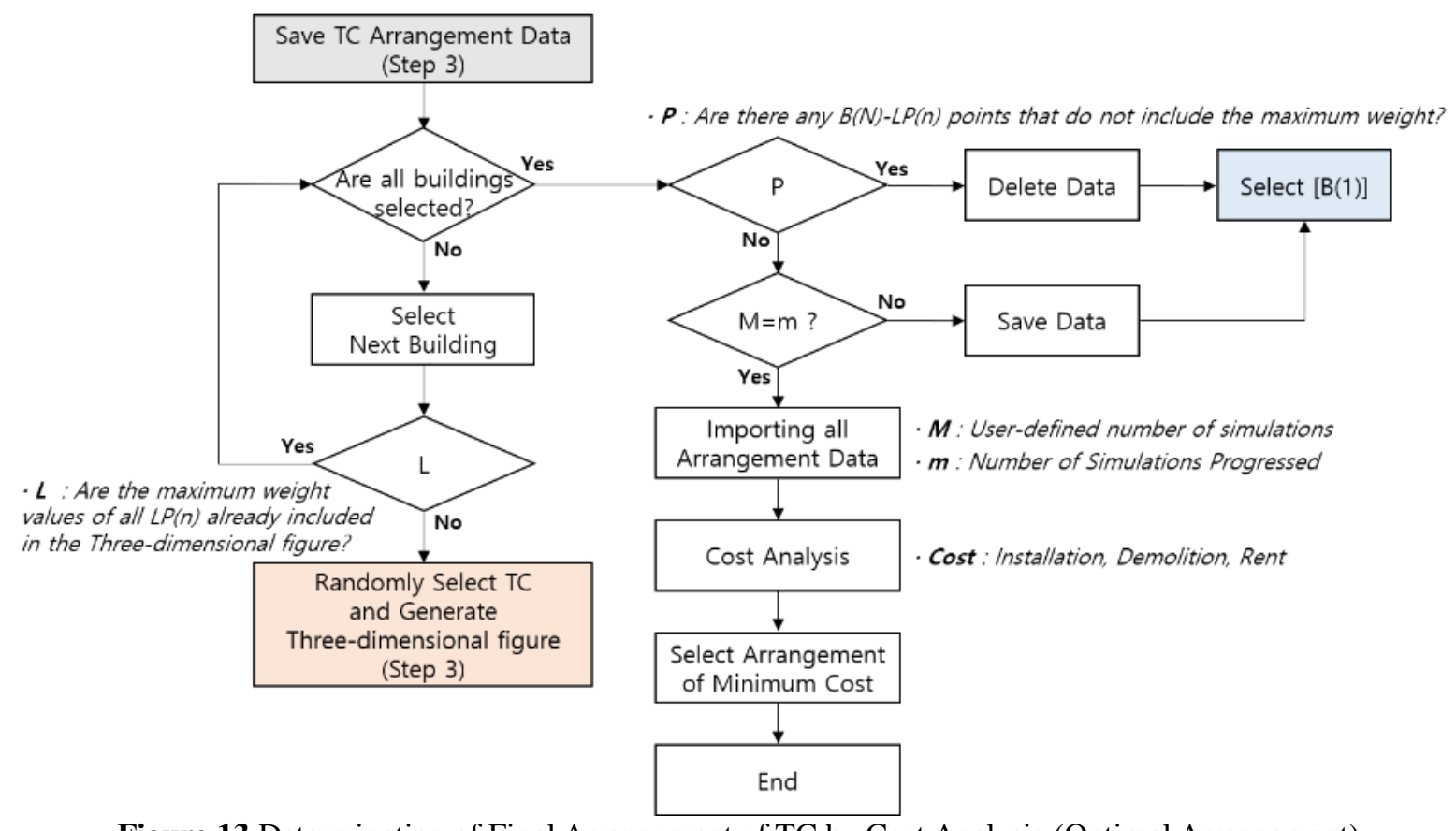

Figure 13 Determination of Final Arrangement of TC by Cost Analysis (Optimal Arrangement)

However, if the arrangement has already been considered for all buildings at this time, the algorithm will proceed according to the decision ' $\mathrm{P}$ '. If the building of $\mathrm{B}(2)$ is selected, it shall go through the process of the decision ' $L$ '. The decision ' $L$ ' is the step of asking whether the 'maximum weight values' of all LP(n) of the selected building are included in the previously arranged 'three-dimensional figure'. If the arrangement is performed as shown in Fig. 14, the arrangement of the 'three-dimensional figure' in $\mathrm{B}(2)$ is not taken into consideration, and the process proceeds to the step of selecting the next building of $\mathrm{B}(3)$. However, if not, it will proceed to the tower crane random selection and 'three-dimensional figure' generation steps of the algorithm step 3.

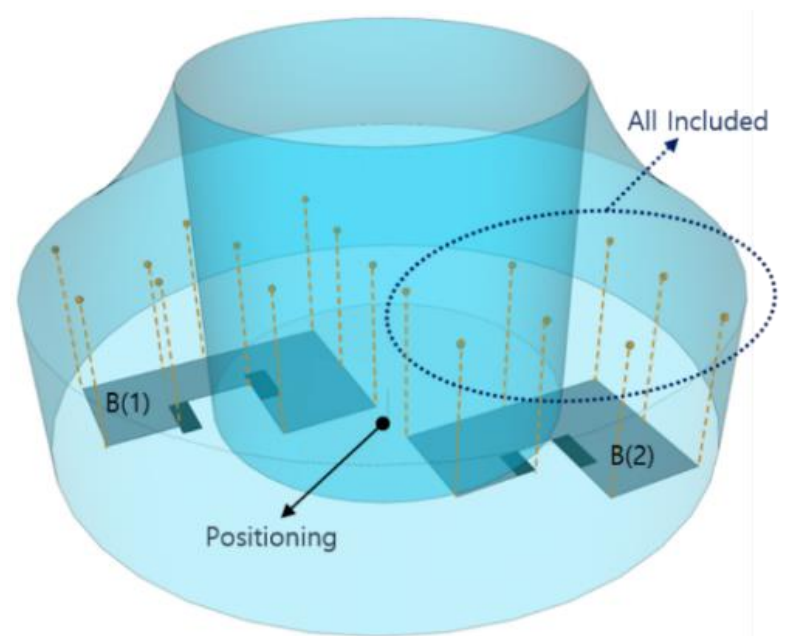

Figure 14 In case the Lifting Work is Unnecessary for All LP(n) of the Building

On the other hand, if the arrangements for all buildings have already been considered, the algorithm proceeds according to the process of the decision ' $\mathrm{P}$ '. In the decision ' $\mathrm{P}$ ', it will decide whether the 'maximum weight value' of LP(n) exists that is not included after the arrangement is complete. If the 'maximum weight value' is not included, all arrangement information is deleted and the process proceeds to the selection step of $\mathrm{B}(1)$.

However, if all of them are included, the arrangement information is saved, and if the number of simulations performed at this time is same with the number of simulations (M) decided by the user, the number of $M$ simulation results which were saved previously are loaded. After that, the simulation that can arrange the tower crane at the minimum cost through the cost analysis is selected from the simulation results of $\mathrm{M}$, and the algorithm is finished. 
At that time, the cost analysis proceeds based on the tower crane installation cost, removal cost, and rent information. Fig. 15 is an example of the simulation finally selected by the algorithm. As shown in Fig. 15, the types of applicable tower cranes vary depending on the lifting capacity, which results in a very complex arrangement. The automatic arrangement algorithm of the tower crane proposed in this study provides a basic framework for effectively consideration of diverse and complex arrangements in terms of cost.

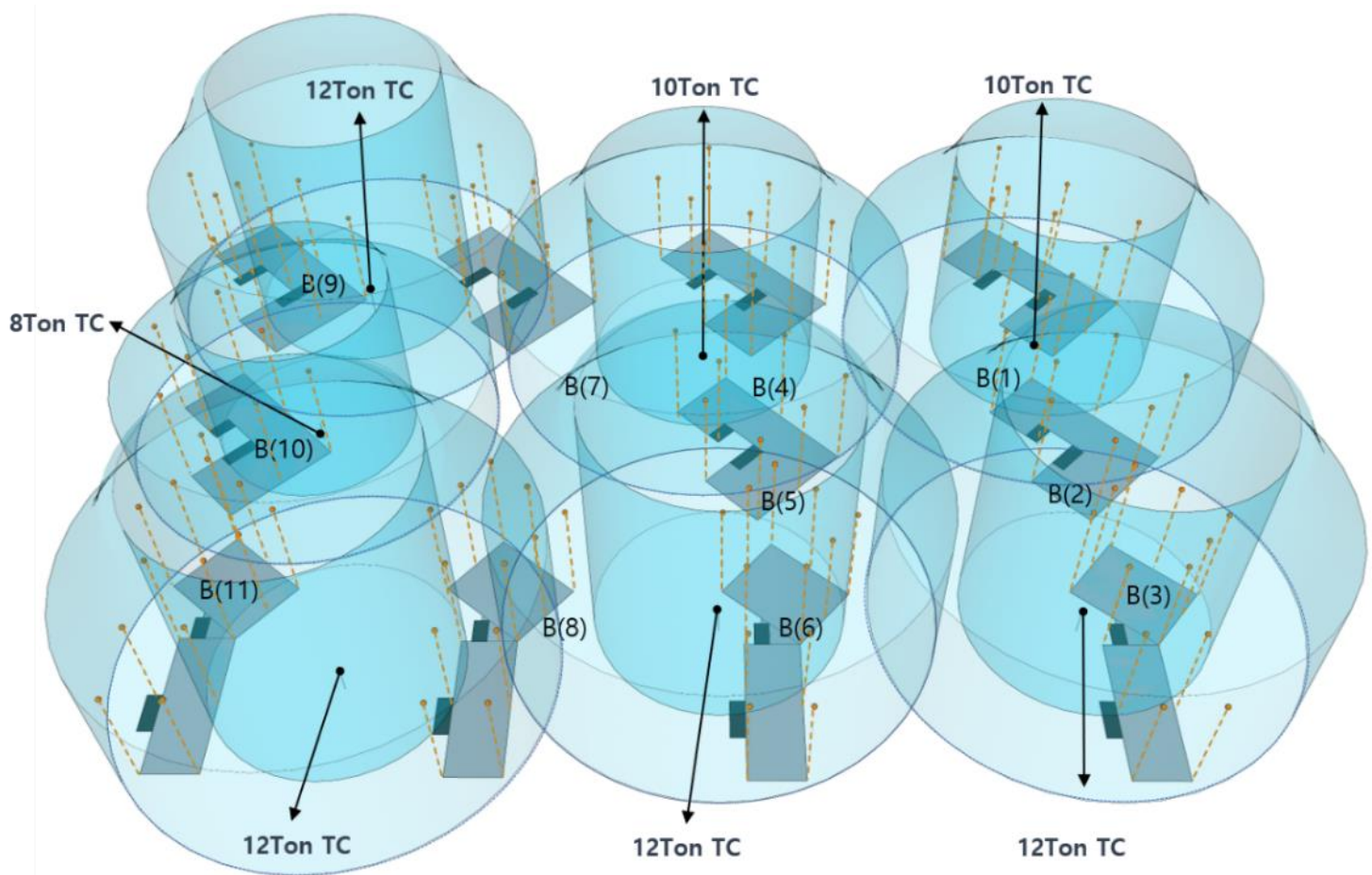

Figure 15 Example of Arrangement Result of Three-dimensional figure

\section{Conclusions}

This study applied a new concept 'lifting limit axis' and developed an automatic arrangement algorithm for tower cranes. We are working in 3D to apply the concept of 'lifting limit axis', which is a different approach than the previous studies done in 2D. The 'lifting limit axis' is a concept that allows the tower cranes to be arranged in consideration of changes in the 'lifting capacity' depending on the working radius of the tower cranes, and enables stable lifting work of the tower crane. The algorithm developed by applying such 'lifting limit axis' is composed of all four steps and the arrangement of the tower crane is determined in the final fourth step.

At this time, the arrangement of the tower crane is selected from many simulation results by the arrangement method requiring the least cost, and the algorithm is finished. However, the selection and arrangement of the tower crane must be decided by analyzing various factors such as the size of the foundation plate, the length of $\mathrm{jib}$, the cost, the position of the open space, and the transportation time. Therefore, the algorithm developed in this study is in a very basic stage, and further research is required to improve various factors and to consider the concept of 'lifting limit axis' in a composite manner. Through further studies, it may develop an automatic tower crane arrangement system and find out an optimal arrangement measure. This is a system that applies the concept of 'lifting limit axis', and the following effects can be expected.

1. It can consider a stable lifting work of the tower crane by applying the concept of 'lifting limit axis'.

2. It can reduce the cost significantly through the algorithm that selects the minimum cost arrangement plan.

3. Unlike conventional methods that rely on expert experience, the automated arrangement method can reduce mistakes and reduce the construction period through efficient arrangement.

\section{Acknowledgements}

- This work is supported by the Korea Agency for Infrastructure Technology Advancement(KAIA) grant funded by the Ministry of Land, Infrastructure and Transport (Grant 20CTAP-C151959-02).

- This work was supported by the National Research Foundation of Korea(NRF) grant funded by the Korea 
government(MSIT)(2017R1C1B5076057).

\section{References}

1. Yun SH, Park CW, Lee G, Kim BK. A Study on a Method for Tracking Lifting Path of a Tower Crane using GPS in the BIM Environment. Journal of the Architectural Institute of Korea Structure \& Construction. 2008 Jun;24(6):163-170. Available from: http://www.dbpia.co.kr/journal/articleDetail?nodeId=NODE01031008.

2. Lee HS, Chae HD, Jang MH. Development of Tower Crane Planning Process in High-rise Building Projects. Journal of the Architectural Institute of Korea Structure \& Construction. 2002 Jun;18(6):119126. Available from: http://www.dbpia.co.kr/journal/articleDetail?nodeId=NODE00365692.

3. Lee JH, Park SJ, Oh SW, Kim YS. A Study on the Work Efficiency Improvement of Tower Crane Operation Using GPS and Machine Vision. Journal of the Architectural Institute of Korea Structure \& Construction. 2002 Nov;18(11):133-140. Available from: http://www.dbpia.co.kr/journal/articleDetail?nodeId=NODE00365792.

4. Cho JH, Cho HG. An Analysis of Optimized Super Tall Building Tower Crane Selection Which Related with Project Construction Period. Journal of the Korea Institute of Building Construction. 2011 Dec;9(6):131-139. Available from: http://kiss.kstudy.com/thesis/thesis-view.asp?key=3439782.

5. Lee UK, Kim JY, Seo DS, Kang KI. Genetic Algorithms of Planning Transportation -Focused on Tower Crane-. Journal of the Architectural Institute of Korea Structure \& Construction. 2004 Feb;20(2):127-134. Available from: http://www.dbpia.co.kr/journal/articleDetail?nodeId=NODE00529147.

6. Lee DW, Hyun HS, Park MS, Lee HS. Tower Crane Location and Capacity Selection Model for the Mid-to-high-rise Modular Construction. Journal of the Architectural Institute of Korea Structure \& Construction. $2016 \quad$ Nov;32(11):27-36. Available from: http://www.dbpia.co.kr/journal/articleDetail?nodeId=NODE07064644.

7. Zhang P, Harris FC, Olomolaiye PO, Holt GD. Location Optimization for a Group of Tower Cranes. Journal of Construction Engineering and Management. 1999 Mar;125(2):115-122. DOI: https://doi.org/10.1061/(ASCE)0733-9364(1999)125:2(115).

8. Rodriguez-Ramos WE, Francis RL. Single Crane Location Optimization. Journal of Construction Engineering and Management. 1983 Dec;125(2):115-122. DOI: https://doi.org/10.1061/(ASCE)07339364(1983)109:4(387).

9. Kim KJ, Kim KM, Lee SK. Optimization of Multiple Tower Cranes and Material Stockyards Layout. Korean Institute of Construction Engineering and Management. 2009 Nov;10(6):127-134. Available from: https://www.koreascience.or.kr/article/JAKO200908856859680.page.

10. Tam CM, Tong TK, Chan WK. Genetic Algorithm for Optimizing Supply Locations around Tower Crane. Journal of Construction Engineering and Management. 2001 Aug;127(4):315-321. DOI: https://doi.org/10.1061/(ASCE)0733-9364(2001)127:4(315).

11. Lim CY, Seo DS, Kim SK. Automatic Arrangement Algorithm for Tower Cranes Used in High-rise Apartment Buildings. Journal of the Korea Institute of Building Construction 2012 Jun;12(3):358-368. DOI: $10.5345 / J K I B C .2012 .12 .3 .358$.

12. Cho JY, Kim SH. Analysis on the Structural Safety of the Tower Crane under Load. Journal of the Korea Academia-Industrial cooperation Society. 2010 Oct;11(10):3641-3646. Available from: http://www.dbpia.co.kr/pdf/pdfView.do?nodeId=NODE07210392\&mark=0\&bookmarkCnt=0\&ipRang $\mathrm{e}=\mathrm{N} \&$ accessgl $=\mathrm{Y} \&$ language $=\mathrm{ko} \_\mathrm{KR}$

13. Yu SN, Kim BH, Han CS. Development of the Semi-Automation System for Tower Crane using Position Measuring Device and Carriage Control Algorithm. Journal of the Architectural Institute of Korea Structure \& Construction. 2005 Dec;21(12):157-166. Available from: http://www.dbpia.co.kr/journal/articleDetail?nodeId=NODE00667240. 